Case Reports in
Gastroenterology
Case Rep Gastroenterol 2021;15:188-194

DOI: $10.1159 / 000512425$

Published online: February 16, 2021 (c) 2021 The Author(s)

Published by S. Karger AG, Basel www.karger.com/crg

This article is licensed under the Creative Commons Attribution-NonCommercial 4.0 International License (CC BY-NC) (http://www.karger.com/Services/OpenAccessLicense). Usage and distribution for commercial purposes requires written permission.

\title{
Perforated Acute Appendicitis in a Six-Day-Old Neonate: A Rare Differential Diagnosis of Neonatal Peritonitis
}

\author{
Thanh Xuan Nguyen ${ }^{a} \quad$ Nhu Thanh Dang ${ }^{b}$ Hai Thanh Phan ${ }^{a}$ \\ Nhu Hien Pham ${ }^{\mathrm{a}}$ Hoai Anh Vu \\ aDepartment of Abdominal Emergency and Pediatric Surgery, Hue Central Hospital, \\ Hue City, Vietnam; 'burgery Department, Hue University of Medicine and Pharmacy, \\ Hue City, Vietnam
}

\section{Keywords}

Appendicitis · Neonates · Sepsis · Surgery

\begin{abstract}
Acute appendicitis is a rare diagnosis of acute abdomen in neonates which is associated with high mortality due to late diagnosis. Here, we presented a case of acute neonatal appendicitis in a 6-year-old full-term infant with Down syndrome and pulmonary atresia with ventricular septal defect. The patient underwent surgery and postoperative critical care. However, he died on postoperative day 5 due to worsening sepsis and decompensated hemodynamic instability.

(C) 2021 The Author(s)
\end{abstract}

Published by S. Karger AG, Basel

\section{Introduction}

The precise diagnosis and timely treatment of abdominal sepsis in neonates is the key to improving outcomes in this fragile population. However, diagnosis remains challenging due to the inability to obtain history, the lack of specific signs and symptoms, and the limited performance of radiological investigations. Peritonitis in this age group can be due to necrotizing

Hai Thanh Phan
Department of Abdominal Emergency and Pediatric Surgery
Hue Central Hospital
16 Le Loi Street, Hue City 530000 (Vietnam)
phanhaithanhvn@yahoo.com




\section{Case Reports in Gastroenterology}

Case Rep Gastroenterol 2021;15:188-194 DOI: $10.1159 / 000512425$

(c) 2021 The Author(s). Published by S. Karger AG, Basel www.karger.com/crg

Nguyen et al.: Perforated Acute Appendicitis in a Six-Day-Old Neonate

enterocolitis (NEC), complications of intestinal obstruction, as well as iatrogenic gastric and duodenal perforations [1]. Neonatal appendicitis (NA) is extremely rare and can be easily overlooked, leading to a high mortality rate of $28 \%$ [2]. Most reported cases in the literature were diagnosed intraoperatively or during postmortem autopsies and were associated with prematurity and significant comorbidities [3]. Here, we report a case of perforated acute appendicitis in a 6-day-old full-term neonate with Down syndrome and pulmonary atresia with ventricular septal defect (PA-VSD) at our hospital.

\section{Case Report}

A 3,000-g boy was born by Cesarean section at $38^{+4}$ weeks of gestation to a 35 -year-old mother. The patient had been diagnosed by prenatal ultrasound at 5 months of gestation with Down syndrome and PA-VSD. The mother had no antenatal history of infection or other medical or surgical illnesses. The patient appeared icteric and cyanotic at birth with an $\mathrm{SpO}_{2}$ of $78 \%$ on room air. Continuous intravenous prostaglandin at $10 \mu \mathrm{g} / \mathrm{kg} / \mathrm{min}$ was used to maintain ductus arteriosus patency. He was transferred to the neonatal intensive care unit. He was passing meconium normally. Initial blood test showed normal complete blood count, unconjugated hyperbilirubinemia in accordance with physiologic jaundice, mildly elevated C-reactive protein of $10.0 \mathrm{mg} / \mathrm{L}$, normal renal function test, and mild electrolyte disturbance.

On the 5th day, the patient developed abdominal distention and refused to feed. On examination, he developed a fever of $38.5^{\circ} \mathrm{C}$. There was no tachypnea. Oxygen saturation was at $60-70 \%$ on $3 \mathrm{~L}$ of oxygen. The lung was clear to auscultation. The abdomen was distended without obvious tenderness or erythema. Bowel sounds were hypoactive. Abdominal X-ray and ultrasound were performed and revealed no pneumoperitoneum or free fluid and no intestinal pneumatosis or portal venous gas (Fig. 1). His blood test showed a normal leukocyte count of $4,210 / \mu \mathrm{L}$. A diagnosis of NEC, Bell stage IA was made and he was put on empiric intravenous antibiotics with ceftriaxone, amikacin, and metronidazole. He was kept nil by mouth and a nasogastric tube was inserted with intermittent suction.

On the 6th day, the abdominal distention increased. There was generalized tenderness and erythema of the abdomen on examination (Fig. 2). No blood was found on per rectal examination. A repeat abdominal ultrasound was made and revealed pneumoperitoneum and moderate ascites. The bowel loops were distended up to $28 \mathrm{~mm}$. No portal venous gas or pneumatosis intestinalis was detected. A repeat blood test showed a leukocytosis of $11,780 / \mu \mathrm{L}$ with $68.1 \%$ neutrophils. C-reactive protein was markedly elevated at $224.3 \mathrm{mg} / \mathrm{L}$. A diagnosis of peritonitis due to perforated hollow viscus was made and he was rapidly transferred for exploratory laparotomy.

A midline incision was made. The entire bowel loops (small intestine, colon) were distended. The peritoneal cavity was filled with turbid and yellowish fluid at all four quadrants. Fibrinous exudate was distributed mainly at the right iliac fossa around the cecum (Fig. 3). The appendix was inflamed and perforated at its middle portion. Other organs in the abdomen were carefully examined and no further lesions could be found. A Vicryl 2.0 suture was used to secure the base and the appendix was transected by scalpel. The peritoneal cavity was irrigated with a large amount of warm normal saline and peritoneal fluid was sent for culture. Peritoneal drainage was placed at the Douglas pouch. The abdomen was closed by interrupted suture.

\section{Karger'"}




\section{Case Reports in Gastroenterology}

Case Rep Gastroenterol 2021;15:188-194

DOI: $10.1159 / 000512425$

(c) 2021 The Author(s). Published by S. Karger AG, Basel www.karger.com/crg

Nguyen et al.: Perforated Acute Appendicitis in a Six-Day-Old Neonate

Pathologic analysis of the appendix demonstrated a grossly inflamed appendix measuring $4 \mathrm{~mm}$ in diameter and $2.5 \mathrm{~cm}$ in length. Microscopic analysis showed marked infiltration of inflammatory cells, including degenerated neutrophils and lymphocytes. The appendiceal mucosa was completely necrotic (Fig. 4).

The patient was transferred to the surgical intensive care unit. Empiric broad-spectrum antibiotic therapy was continued using meropenem and amikacin. However, the patient died on postoperative day 5 due to worsening sepsis and decompensated hemodynamic instability.

\section{Discussion}

Acute appendicitis is a rare cause of acute abdomen in the neonatal period, with a reported incidence ranging from 0.04 to $0.2 \%$ and with a male:female ratio of $3: 1$ [3, 4]. While the most common diagnosis of neonatal peritonitis is NEC with the reported incidence ranging from 2 to $7.5 \%$, many cases of NA were initially misdiagnosed as NEC, as in our case [5]. The rarity of NA is considered to be multifactorial. Possible explanations include funnel-shaped rather than tubular appendix, liquid diet, infrequent viral infection, and recumbent positioning [6].

The etiology of NA also remains to be elucidated. There are, however, three different hypotheses in the literature. Some authors argued that NA is a localized form of NEC [7]. Others suggest that impaired vascular supply to the appendix can lead to perforation in conditions such as cardiac anomalies or other low-flow or hypoxic states. The third hypothesis is that NA is caused by cecal distention due to meconium ileus or Hirschsprung disease [8]. The second hypothesis might partly explain the perforation of the appendix in our case since PA-VSD leads to a low-oxygen state, which predisposes the appendix to ischemia and perforation. This was further confirmed by the extensive transmural necrosis of the appendix on the specimen. PAVSD is also a rare condition, with an incidence of $0.7 / 10,000$ live births in one study. PA-VSD is considered the most severe type of tetralogy of Fallot. Our patient also had Down syndrome (trisomy 21), which was suspected on prenatal ultrasound and confirmed by genetic testing. Down syndrome was also reported as a condition associated with NA in one case report [9].

Although significant improvement in perinatal care has been achieved, the mortality of NA remains as high as $28 \%$. This reflects the diagnostic challenge before perforation and peritonitis occur [10]. One of the reasons is that the presenting signs and symptoms of NA are nonspecific, including abdominal distention (75\%), vomiting (42\%), decreased oral intake $(40 \%)$, sepsis (38\%), temperature instability (33\%), lethargy or irritability (24\%), abdominal wall cellulitis $(24 \%)$, respiratory distress $(15 \%)$, abdominal mass $(12 \%)$, and hematochezia $(10 \%)$ [2]. The majority of these signs and symptoms demonstrate significant overlap with other more common causes of neonatal acute abdomen, including NEC or bowel obstruction.

The low yield of preoperative investigation also contributes to the delay in diagnosis of NA. Free fluid and mass in the right lower quadrant can be seen on $8 \%$ of cases but are not pathognomonic for appendicitis. The findings on plain radiography are also nonspecific. The single most important sign which determines the therapeutic approach is pneumoperitoneum, which can be seen in $52 \%$ of cases. However, this is also a late presentation when appendiceal perforation and peritonitis have occurred [11]. Schwartz et al. [2] suggested use of an urgent computed tomography scan when ultrasound and plain radiograph are inconclusive to facilitate the diagnosis of acute abdomen in infants. It has been proved to have superior sensitivity and specificity for appendicitis at all ages [12].

\section{Karger'=}




\section{Case Reports in Gastroenterology} \begin{tabular}{l|l}
\hline DOI: 10.1159/000512425 & $\begin{array}{l}\text { ○ } 2021 \text { The Author(s). Published by S. Karger AG, Basel } \\
\text { www.karger.com/crg }\end{array}$
\end{tabular}

Nguyen et al.: Perforated Acute Appendicitis in a Six-Day-Old Neonate

In conclusion, NA remains a rare disease with frequent late diagnosis and a high mortality rate. Further studies are required to clarify its etiology and to determine a better approach to diagnosing NA in a timely manner.

\section{Statement of Ethics}

The institutional review board of Hue Central Hospital approved this case study. Written informed consent for publication of this case report and any accompanying images was obtained from the parents.

\section{Conflict of Interest Statement}

The authors declare no financial disclosures or conflicts of interest.

\section{Funding Sources}

There were no funding sources.

\section{Author Contributions}

T.X. Nguyen and H.T. Phan carried out and confirmed the diagnosis, provided the details of the case, and contributed to the design of the report. T.X. Nguyen, N.T. Dang, and H.T. Phan drafted the manuscript. N.H. Pham and H.A. Vu revised it critically for important intellectual content. All authors read and approved the final version of the manuscript.

\section{References}

1 de la Hunt MN. The acute abdomen in the newborn. Semin Fetal Neonatal Med. 2006 Jun;11(3):191-7.

2 Schwartz KL, Gilad E, Sigalet D, Yu W, Wong AL. Neonatal acute appendicitis: a proposed algorithm for timely diagnosis. J Pediatr Surg. 2011 Nov;46(11):2060-4.

3 Jancelewicz T, Kim G, Miniati D. Neonatal appendicitis: a new look at an old zebra. J Pediatr Surg. 2008 Oct; 43(10):e1-5.

4 Arora NK, Deorari AK, Bhatnagar V, Mitra DK, Singhal PK, Singh M. Neonatal appendicitis: a rare cause of surgical emergency in preterm babies. Indian Pediatr. 1991 Nov;28(11):1330-3.

5 Rees CM, Eaton S, Pierro A. National prospective surveillance study of necrotizing enterocolitis in neonatal intensive care units. J Pediatr Surg. 2010 Jul;45(7):1391-7.

6 Schorlemmer GR, Herbst CA Jr. Perforated neonatal appendicitis. South Med J. 1983 Apr;76(4):536-7.

7 Kwong MS, Dinner M. Neonatal appendicitis masquerading as necrotizing enterocolitis. J Pediatr. 1980 May;96(5):917-8.

8 Arliss J, Holgersen LO. Neonatal appendiceal perforation and Hirschsprung's disease. J Pediatr Surg. 1990 Jun;25(6):694-5.

9 Giacomoni MA, Manzoni GA, Volpi ML. Perforated appendicitis in a newborn infant associated with Down's syndrome. Review of the literature. Pediatr Med Chir. 1986 Jan-Feb;8(1):113-4. Italian.

10 Karaman A, Cavuşoğlu YH, Karaman I, Cakmak O. Seven cases of neonatal appendicitis with a review of the English language literature of the last century. Pediatr Surg Int. 2003 Dec;19(11):707-9.

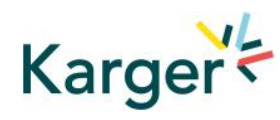


Case Reports in Gastroenterology
Case Rep Gastroenterol 2021;15:188-194

DOI: $10.1159 / 000512425$

(c) 2021 The Author(s). Published by S. Karger AG, Basel www.karger.com/crg

Nguyen et al.: Perforated Acute Appendicitis in a Six-Day-Old Neonate

11 Raveenthiran V. Neonatal Appendicitis (Part 1): A Review of 52 cases with Abdominal Manifestation. J Neonatal Surg. 2015 Jan;4(1):4.

12 van Randen A, Bipat S, Zwinderman AH, Ubbink DT, Stoker J, Boermeester MA. Acute appendicitis: metaanalysis of diagnostic performance of CT and graded compression US related to prevalence of disease. Radiology. 2008 Oct;249(1):97-106.

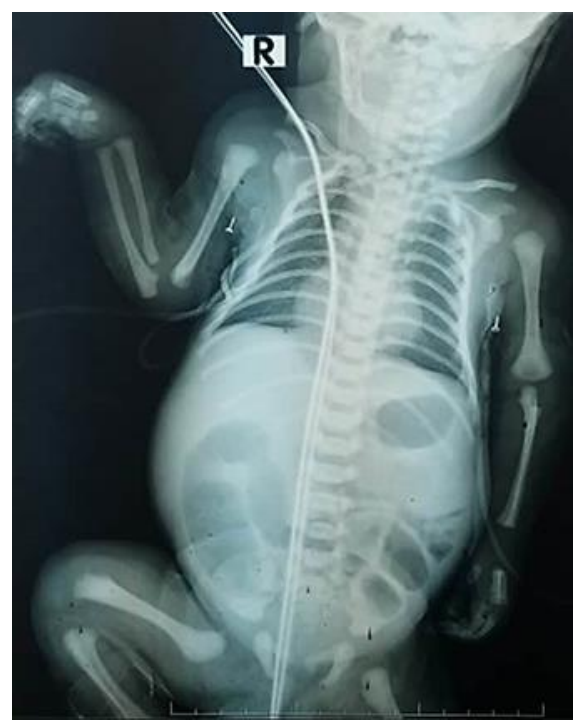

Fig. 1. Plain radiograph showed dilated bowel loop, no pneumatosis intestinalis, no free gas, and no portal venous gas. 
Case Reports in Gastroenterology
Case Rep Gastroenterol 2021;15:188-194

DOI: $10.1159 / 000512425$

(c) 2021 The Author(s). Published by S. Karger AG, Basel www.karger.com/crg

Nguyen et al.: Perforated Acute Appendicitis in a Six-Day-Old Neonate

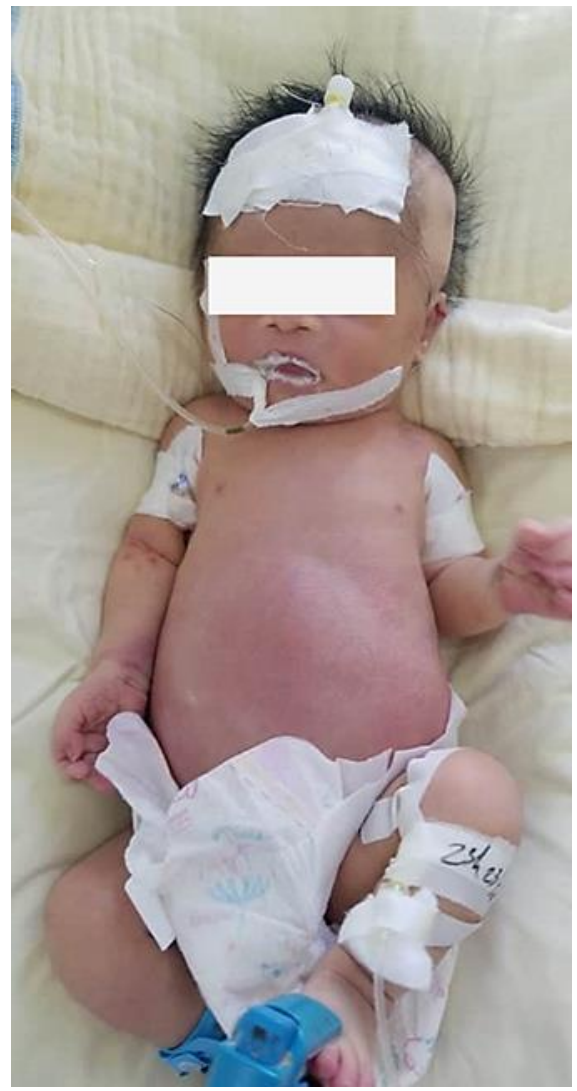

Fig. 2. The abdomen was distended and abdominal wall erythema was present.

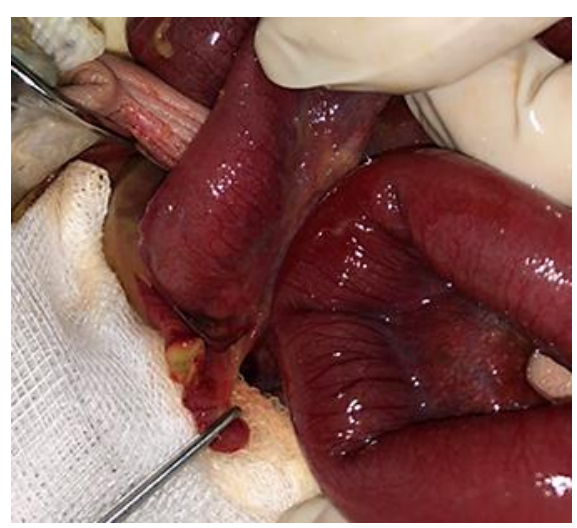

Fig. 3. Intraoperative image of perforated appendicitis at the middle third of the appendix. Adjacent yellowish fluid with fibrinous exudate can be seen. 
Case Reports in Gastroenterology
Case Rep Gastroenterol 2021;15:188-194

DOI: $10.1159 / 000512425$

(c) 2021 The Author(s). Published by S. Karger AG, Basel www.karger.com/crg

Nguyen et al.: Perforated Acute Appendicitis in a Six-Day-Old Neonate

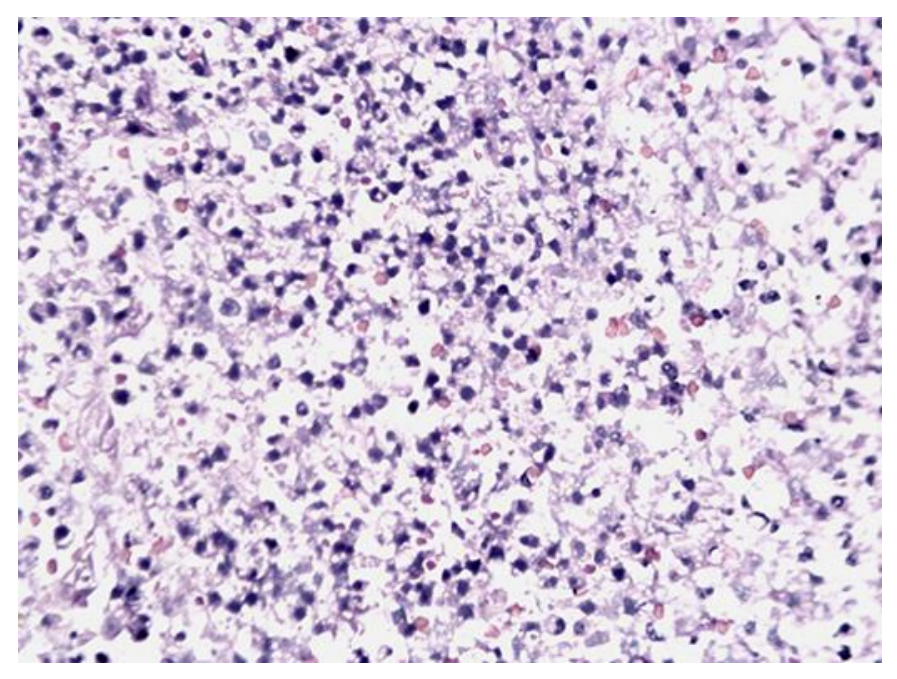

Fig. 4. Histopathologic examination revealed infiltration of neutrophils and widespread necrosis of the appendix $(H \& E, \times 400)$. 